\section{EMBRYRIDDLE \\ Aeronautical University}

SCHOLARLY COMMONS

\section{International Journal of Aviation,} Aeronautics, and Aerospace

\title{
Effects of the Pilot Shortage on the Regional Airline Industry: A 2023 Forecast
}

\author{
Ethan S. Klapper \\ Embry-Riddle Aeronautical University, klappee1@my.erau.edu \\ Hans-Joachim K. Ruff-Stahl \\ Embry-Riddle Aeronautical University, ruffha@erau.edu
}

Follow this and additional works at: https://commons.erau.edu/ijaaa

Part of the Other Business Commons, and the Tourism and Travel Commons

\section{Scholarly Commons Citation}

Klapper, E. S., \& Ruff-Stahl, H. K. (2019). Effects of the Pilot Shortage on the Regional Airline Industry: A 2023 Forecast. International Journal of Aviation, Aeronautics, and Aerospace, 6(3). https://doi.org/ 10.15394/ijaaa.2019.1321

This Article is brought to you for free and open access by the Journals at Scholarly Commons. It has been accepted for inclusion in International Journal of Aviation, Aeronautics, and Aerospace by an authorized administrator of Scholarly Commons. For more information, please contact commons@erau.edu. 
In the next 5 years and beyond, it is predicted that the U.S. airline industry will face a substantial pilot shortage. Pilots in the US mandatorily retire at the age of 65, while at the same time, the barriers to entry to earning an FAA airline transport pilot (ATP) certificate have arguably never been higher, with training costs increasing and new minimum-hour requirements taking effect in 2013. Regional airlines, which provide a significant stream of new pilots to the major airlines operating under Part 121, will be hit the hardest, as major airlines ramp up hiring from the regional airlines to replace pilots who are retiring.

Given the important impact of regional airlines in supplying pilots to the major airlines, a regional pilot shortage could have devastating effects for the overall U.S. airline industry, and the broader U.S. economy. In other words, a near-term shortage of regional pilots could have longer-term effects in the industry.

This nonexperimental study focused on those near-term effects by asking how many aircraft will have to be taken out of service by 2023 if the pilot shortage materializes, and how many passengers that loss of aircraft will impact. Building on research conducted by Higgins et. al. (2013) and later updated by Higgins, Bjerke, Lovelace, and Leonard (2016), three different regional pilot shortage scenarios are explored for 2023. From there, a model is created that predicts how many regional aircraft will need to be taken out of service, based on the deficit of pilots. Since the number of aircraft a regional airline has in service is correlated to the number of passengers it carries, the loss in passengers for the regional airline industry is then predicted. This metric is important, because it shows the corresponding loss in demand when supply is cut. Then, the results are put in context, and a discussion of impacts and possible strategies to mitigate the pilot shortage follows.

\section{Review of Literature}

Higgins et al. (2013) created a widely-cited academic model that projects the cumulative deficit of airline pilots in the US, and it provides the foundation for this study. It is a supply-side model that bases its projection on the number of pilots earning certified flight instructor (CFI) ratings, as instructing is a popular way for civilian pilots to build time and, according to the study's authors, $84 \%$ of ATP certificate holders also hold (or have held) a CFI rating.

In addition to its supply-side model, the forecast also factors in the demand side by predicting how many new pilots will be needed. It does this by accounting for mandatory pilot retirements at age 65, attrition due to a pilot losing his/her medical certificate, as well as other voluntary or involuntary factors. The work of Higgins et al. in 2016 is an update to their 2013 research, and projects a 
cumulative industrywide deficit of around 8,000 airline pilots by 2023, and 14,439 airline pilots by 2026.

Further complicating the supply of pilots is the fact that regional airlines are hiring CFIs away from flight schools faster than they can be replaced, according to the U.S. Government Accountability Office (Von Ah, 2018). A lack of CFIs indicates there will be a pilot shortage further up the supply chain and is another ominous data point when talking about a pilot shortage in 2023 and beyond. The GAO report also encountered some of the same data limitations that this study encountered.

Forbes and Lederman (2006) provided a practical overview of the role that regional airlines play in the U.S. air transportation system. While this paper is over a decade old, it provides important background on the business relationships between regional airlines and the mainline airlines that work with the regional airlines, a relationship explored more in-depth later on.

In August 2013, new FAA regulations took effect, requiring all fight crew members operating for a Part 121 air carrier to have an ATP certificate. An ATP certificate requires 1,500 hours (though that minimum lowers when one has a restricted ATP certificate (R-ATP), which is awarded through a combination of flying time and higher education or military experience). The 2015 Pilot Source Survey analyzed new hires at 19 regional airlines since the new regulations took effect, and compared the data to similar studies conducted before the regulations were implemented. The study found that 17\% of the pilots hired in August 2013 or afterward had R-ATP certificates, compared to $83 \%$ having full ATP certifications (Bjerke et. al., 2016). The study, which had industry participation, provides a high-level statistical overview of the backgrounds of regional pilots and provides a model for future research.

While Bjerke et. al. (2016) conducted a comprehensive study involving the background of hired regional pilots, no such study exists for the pilots that major airlines hire. Therefore, it is difficult to precisely quantify the exact source of new hires for major airlines, but generally speaking, regional airlines provide a large majority of new pilots for major airlines. For example, half of American Airlines' new hires come from pilots "flowing through" from its three whollyowned regional airlines, essentially giving pilots a guaranteed job at American Airlines down the road when they're hired by one of American's regionals (PSA Airlines, n.d.). While American's program is the most significant, other regional airlines have career path programs that at the very least give regional pilots a guaranteed interview at a major airline; it is fair to say the infrastructure exists to enable regional pilots to advance to the majors. In addition, retired military aviators are historically a significant source of new pilots for major airlines, but that number has slowed in recent years (Svitak, 2012). 
Approximately $78 \%$ of potential airline pilots make a cost-benefit analysis when considering a career as an airline pilot (Higgins et. al., 2013). This involves weighing economic costs of the career (expensive training, initially low pay) with the potential economic benefits (considerably higher pay later on in one's career). As a result, there is strong incentive for regional airline pilots to accept job offers at major airlines, and with the demand side of the pilot shortage driven by accelerating retirements of pilots at major airlines when they turn 65 , it may be assumed that the majority of the pilot shortage will be at regional airlines, but it's unclear just how big it will be.

\section{Method}

Because of this unknown, and the fact this research focuses primarily on the short-term effects of the pilot shortage and not on its causes, three scenarios will be run. The first scenario will be the unlikely event where $100 \%$ of the pilot deficit ( 8,000 industrywide by 2023) consists of regional pilots ("scenario 1"). The second scenario is one where $75 \%$ of the deficit consists of regional pilots ("scenario 2"), and the third scenario is where $66 \%$ of the deficit consists of regional pilots ("scenario 3"). These splits were chosen because they represent the belief that a majority of the pilots in the forecasts of Higgins et al. (2013) will be regional pilots.

The author's intent was to expand on the work of Higgins et al. (2013) by (a) predicting regional airline fleet withdrawals ("aircraft parking") based on the scarcity of pilots; and (b) forecasting the loss in passengers the regional airline industry transports as a result of the pilot shortage. The work of Higgins et al. looks at the industry as a whole, and not regional airlines specifically.

\section{Regional Airline Fleet Withdrawals Based on Pilots Scarcity}

In the US, certificated airlines that fly aircraft with 60 or more seats are required to report certain operating and traffic statistics to the U.S. Department of Transportation (n.d.), a dataset known as Form 41. Included in this comprehensive data is detailed information about airline fleets and airline workforces. This covers all but three regional airlines (

Table 1), and those three airlines were supplemented with similar data from Airline Pilot Central, a frequently-updated website aimed at pilot recruitment. To increase statistical confidence, data for all the current Form 41-reporting airlines dating back to 2008 was entered, bringing $n$ to 123 . 
Table 1

Regional Airlines Included in Analysis, Sorted by USDOT Reporting Status

\begin{tabular}{cc}
\hline Form 41-Reporting Airlines & Non-Form 41-Reporting Airlines \\
\hline Air Wisconsin Airlines Corp. & Piedmont Airlines \\
Compass Airlines & Commutair \\
Endeavor Air Inc. & Trans States \\
Envoy Air & \\
ExpressJet Airlines Inc. & \\
Horizon Air & \\
Mesa Airlines Inc. & \\
Republic Airline & \\
SkyWest Airlines Inc. & \\
PSA Airlines & \\
GoJet &
\end{tabular}

An analysis of regression was computed, and found that airline pilot staffing, $X$, can significantly predict an airline's fleet size, $\hat{Y}, F(1,121)=1918.53, p<.001$, $R^{2}=.941$, with the following equation, $\hat{\mathrm{Y}}=.104 X+2.821$.

\section{Using Fleet Deficit to Calculate Loss of Passengers}

A number of different metrics were considered to illustrate the decline in demand for regional airline service when there's a corresponding drop in supply. Passenger enplanements proved to be the best metric to explore because it shows this decline in the most straightforward fashion, compared to metrics such as available seat miles. To calculate this regression, Form 41 passenger enplanement and fleet data from 2008 to $2017(n=110)$ was used to calculate another analysis of regression, and showed that fleet size, $X$, can be used to significantly predict an airline's passenger enplanements, $\hat{Y}, F(1,108)=1304.22, p<.001, R^{2}=.924$, with the following equation, $\hat{Y}=71699.586 X+1357461.434$.

Unlike the fleet calculation, 2018 data was not included in this calculation because the year had not concluded at the time, and thus final 2018 numbers had yet to be reported on Form 41. Non-Form 41 airlines were also not included because this data is unavailable for those airlines.

\section{Limitations of this Method}

This analysis does not consider a number of factors that could significantly impact its results. This includes economic downturns (either in the airline industry or the broader U.S. economy), industry consolidation, and future 
industry regulatory changes. The results of this study should be interpreted as an extrapolation of a broader airline industry forecast that was conducted in 2016, and an analysis of the effects on the regional airline industry as a result of that extrapolation.

In the event that a study similar to the one that Bjerke et. al. (2016) conducted for the regional airline industry is conducted for major airlines, this methodology should provide a simple framework for higher-confidence results.

\section{Results and Discussion}

Results are summarized in Table 2.

Table 2

Fleet and Passenger Enplanements Impacted by Regional Pilot Shortage Scenarios by 2023

\begin{tabular}{cccc}
\hline Scenario & $\begin{array}{c}\text { Cumulative } \\
\text { Regional Pilot } \\
\text { Deficit }\end{array}$ & $\begin{array}{c}\text { Cumulative } \\
\text { Aircraft Parked }\end{array}$ & $\begin{array}{c}\text { Passenger Loss } \\
\text { (since 2016) }\end{array}$ \\
\hline $\mathbf{1}$ & 8,000 & 835 & $61,226,616$ \\
$\mathbf{2}$ & 6,000 & 627 & $46,313,102$ \\
$\mathbf{3}$ & 5,333 & 557 & $41,294,131$ \\
\hline
\end{tabular}

As expected, the results are highly linear. The larger the deficit of pilots, the more aircraft that the regional airline industry will have to park. Having fewer aircraft to operate due to regional airlines employing fewer pilots to operate them directly corresponds to a loss of passengers. Less demand due to supply-side issues causes revenue issues for major airlines and contractual issues for the regional airlines.

However, these results are part of a broader regional airline industry contraction. Since at least 2009, the U.S. airline industry has been adding capacity while flying fewer planes. This is done by flying larger planes, often ones operated by major airlines as opposed to regional airlines. Meanwhile, as shown in Figure 1, regional airline enplanements have dropped from a high of 164.1 million in 2010 to 153.25 million in 2017 (Regional Airline Association, 2018). 


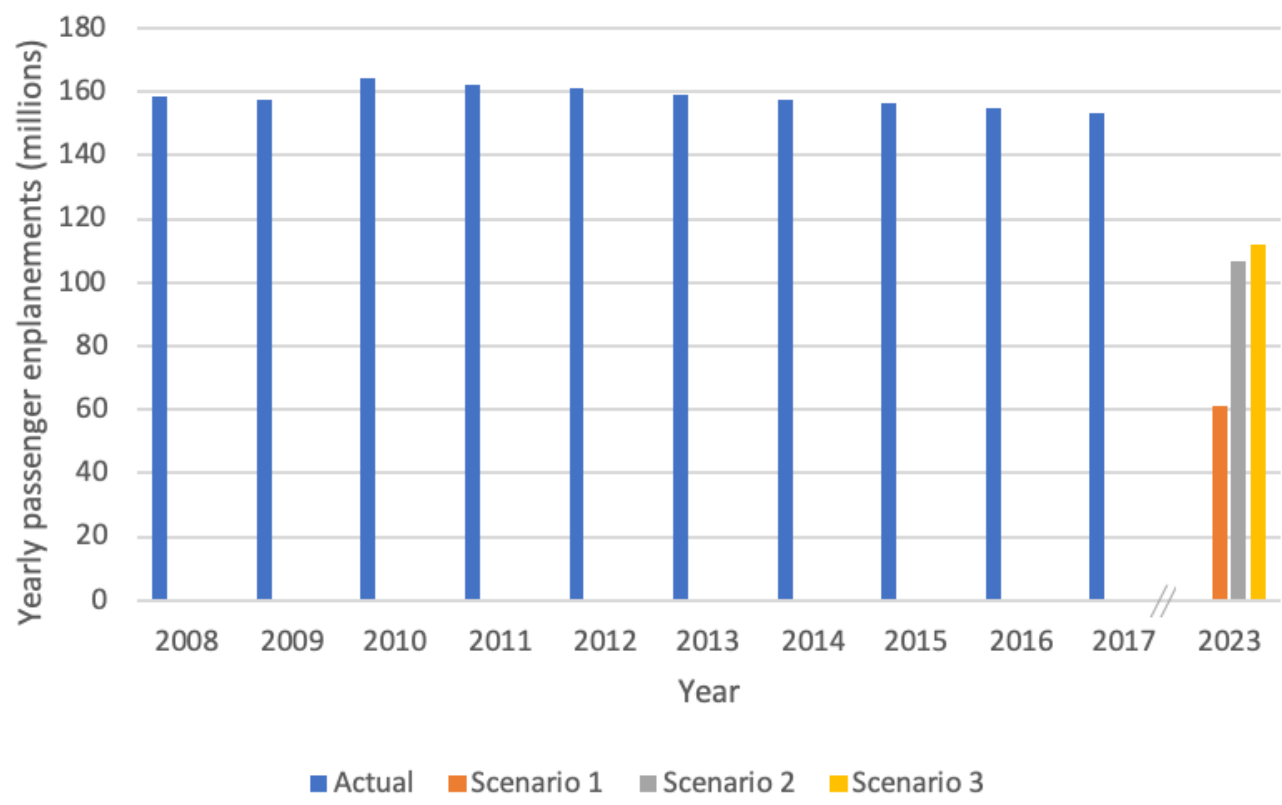

Figure 1. Regional airline passenger enplanement contraction. 2008-2017 data adapted from Regional Airline Association, October 2018 Industry Update.

It is important to contextualize these results - and the broader regional pilot shortage - with an understanding of the regional airline business model. Regional airlines earn their revenue from capacity-purchase agreements (CPA) with major airlines. In a CPA, major airlines pay a fixed, contracted rate to regional carriers for the flights that the regional carriers operate on the major airlines' behalf. The major airlines earn $100 \%$ of the direct revenue from flights that the regional carriers operate, and the regional carriers are largely shielded from demand and cost risk (Forbes \& Lederman, 2006). In other words, a CPA guarantees revenue for a regional airline that enters into one with a major carrier.

When a regional airline lacks pilots to operate flights it is contractually obligated to operate, this becomes a legal issue and can lead to bankruptcy, as was the case with Republic Airways. Republic was stuck in contract negotiations with its pilot union for 8 years. As a result, it was paying pilots well below market rates, and was having severe difficulty recruiting new pilots. Attrition got to the point where Republic did not have enough pilots to operate the flights it was under contract to operate, and it had to park planes. In 2015, Delta sued Republic for breaching its CPA (Associated Press, 2015). At the same time, when Republic and the union reached an agreement (shortly prior to the bankruptcy filing), that required new CPA negotiations with the major airlines, to finance the more expensive collective bargaining agreement (Declaration of Bryan K. Bedford, 2016). 
When Republic restructured following its February 2016 Chapter 11 bankruptcy filing, it emerged as a smaller, privately-held company. The airline ultimately exited bankruptcy in April 2017 (Hemmerdinger, 2017).

While Republic's bankruptcy is an extreme example of an airline-specific pilot shortage, accelerated by an impasse with a key labor union during a time of major change in the industry, it is an important pretext to any discussion about pilot shortages throughout the regional airline industry.

If regional airlines do not have the supply of pilots to fly contracted routes, the airlines will have to park planes, as is forecast here. Parking planes directly impacts the number of passengers that are carried, as is also forecast. That affects the major airlines that are business partners with the regional airlines, since the major airlines earn $100 \%$ of the revenue from CPA flights, and use regional airline capacity as essential components of their overall networks.

As has been the case for a number of years, and a key factor in Republic's bankruptcy, a shortage of pilots leads to higher costs for airlines, because during times of scarcity, airlines are required to offer more incentives, such as higher pay and signing bonuses, to recruit pilots, which costs more money. These costs are passed on to the major airlines through CPAs, as they are renegotiated.

The broader question, and one to answer in subsequent research is if, driven by the pilot shortage and other supply-side costs, the regional airline business model is becoming outdated. For example, Delta Air Lines has replaced some regional flying with secondhand Boeing 717s that have low operating costs due to their lower acquisition costs (Center for Aviation, 2018). "The 717 is very much about how do we get out of the regional jets," Delta's CEO said in late 2017 (Zhang, 2017, The Rebirth section). Those small narrowbodies were later augmented at Delta by Airbus A220-100s (formerly known as the Bombardier CS100), which were said to be purchased at a steep discount, so the operating costs will also be relatively low. Perhaps one way to help solve the pilot shortage is for major airlines to take over more regional-style flying. With first-year first officer pay at major airlines around double that of what's offered at regional airlines (Airline Pilot Central, n.d.), the cost-benefit analysis that pilots initially make about their careers becomes an easier one in this scenario, and perhaps more pilots would have enough economic incentive to join airlines. While costs could initially be higher, airlines would not have to worry about reliability issues, as happened when Delta sued Republic, and it would likely be easier for airlines to recruit pilots. Airlines such as Delta and JetBlue Airways are also now starting to offer career path/cadet programs that either entirely bypass regional airlines or place participants at a regional airline for a fixed amount of time, removing the uncertainty that is also part of that consumer decision (JetBlue, 2018; Simmons, 2018). 


\section{Conclusion}

By 2023, it seems likely the regional airline industry will contract, both in the number of aircraft flying and the number of passengers being carried by those aircraft. A pilot shortage would be a major driving factor for this contraction, though other factors will likely contribute to this contraction.

Some airlines, such as Delta, are taking steps to slowly eliminate traditional regional flying. Delta has a growing fleet of small mainline jets, while at the same time is offering a way for pilots to earn jobs at Delta without the uncertain economics that traditionally deter potential candidates from becoming regional pilots.

New pilot pathway programs will be an important topic in the next few years, and one that deserves more research. Are the efforts of airlines such as Delta and JetBlue enough to fix the overall industry pilot shortage, and at what cost? What other strategies are there to get a new generation of pilots excited about the industry, and to mitigate the high costs of becoming a pilot? 


\section{References}

Airline Pilot Central. (n.d.). Airline profiles. Retrieved from https://www.airlinepilotcentral.com/airlines

Associated Press. (2015, October 8). Delta sues smaller airline over canceled flights. Associated Press. Retrieved from https://www.savannahnow.com/ article/20151008/NEWS/310089841

Bjerke, E., Smith, G., Smith, M., Christensen, C., Carney, T., Craig, P., \& Niemczyk, M. (2016). Pilot source study 2015: US regional airline pilot hiring background characteristic changes consequent to public law 111-216 and the FAA first officer qualifications rule. Journal of Aviation Technology and Engineering, 5(2), 3-14. doi://doi.org/10.7771/2159-6670.1133

Centre for Aviation. (2018). Delta Air Lines: The only US big 3 airline taking 100-seat aircraft. Sydney: Centre for Aviation. Retrieved from https://centreforaviation.com/analysis/reports/delta-air-lines-the-only-us-big3-airline-taking-100-seat-aircraft-431837

Declaration of Bryan K. Bedford Pursuant to Local Bankruptcy Rule 1007-2 at 4. (2016). In re Republic Airways Holdings Inc., et. al., Debtors., (Bankr. S.D.N.Y., 2016) (No. 16-10429).

Forbes, S. J., \& Lederman, M. (2006). The role of regional airlines in the U.S. airline industry. Retrieved from http://faculty.weatherhead.case.edu/ forbes/book_chapter_oct06.pdf

Hemmerdinger, J. (2017, May 1). Republic exits bankruptcy protection as private company. FlightGlobal. Retrieved from https://www.flightglobal.com/ news/articles/republic-exits-bankruptcy-protection-as-private-comp436732/

Higgins, J., Lovelace, K., Bjerke, E., Lounsberry, N., Lutte, R., Friedenzohn, D., . . . Craig, P. (2013). An investigation of the United States airline pilot labor supply. Retrieved from https://www.researchgate.net/publication/ 249315130_An_Investigation_of_the_United_States_Airline_Pilot_Labor_S upply

Higgins, J., Bjerke, E., Lovelace, K., \& Leonard, A. (2016). US airline pilot supply forecast 2016. Grand Forks, ND: University of North Dakota. Retrieved from http://www.airservicealliance.com/wp-content/uploads/ 2017/02/UND-RASA-MTG-IN-MSP.pdf

JetBlue. (2018). Pilot gateway programs. Retrieved from http://pilots.jetblue.com/ 
PSA Airlines. (n.d.). First officers. Retrieved from https://psaairlines.com/firstofficers

Regional Airline Association. (2018). Industry update. Regional Airline Association. Retrieved from https://cdn.ymaws.com/www.raa.org/ resource/resmgr/2018_pubs/20181011_october_update_fina.pdf

Simmons, C. (2018). Delta propels next generation of pilots through innovative career paths. Retrieved from https://news.delta.com/delta-propels-nextgeneration-pilots-through-innovative-career-paths

Svitak, A. (2012, December 18). Industry urges study to highlight pilot shortage. AWIN First. Retrieved from http://aviationweek.com/awin/ industry-urges-study-highlight-pilot-shortage

U.S. Department of Transportation. (n.d.). Air carrier financial reports (form 41 financial data). Retrieved from https://www.transtats.bts.gov/ Tables.asp?DB_ID=135

Von Ah, A. (2018). Collegiate aviation schools: Stakeholders'views on challenges for initial pilot training programs. Washington, DC: Government Accountability Office. Retrieved from https://www.gao.gov/assets/ 700/691748.pdf

Zhang, B. (2017, December 3). How the Boeing jet no one wanted became the plane airlines scour the planet for. Business Insider. Retrieved from https://www.businessinsider.com/boeing-717-jet-delta-hawaiian-qantas2017-12 